\title{
COMPARATIVE STUDY OF ALUMINUM ALLOY 6061 TOOL WITH GRAPHITE, COPPER AND BRASS TOOLS IN EDM
}

\section{B. KISHAN ${ }^{1}$, DR. B. SUDHEER PREM KUMAR ${ }^{2}$, DR. S. GAJANANA ${ }^{3}$,} A. BALARAM NAIK ${ }^{4}$, P.V.K CHAITANYA KUMAR ${ }^{5}$

\author{
${ }^{I}$ Research Scholar, Department of Mechanical Engineering, JNTUH College of Engineering, Hyderabad, Kukatpally, India \\ ${ }^{2}$ Professor, Département of Mechanical Engineering, JNTUH College of Engineering, Hyderabad, Kukatpally, India \\ ${ }^{3}$ Professor, Department of Mechanical Engineering, MVSR Engineering College, Hyderabad, India \\ ${ }^{4}$ Associate Professor, Department of Mechanical Engineering, JNTUH Collège of Engineering, Hyderabad, Kukatpally, India \\ ${ }^{5} U G$ Student, Department of Mechanical Engineering, MVSR Engineering College, Hyderabad, India
}

\begin{abstract}
The machining behavior of Aluminum Alloy 6061 using Electro Discharge Machining (EDM) is the aim to investigate with three different tool materials are Copper, Graphite and Brass. The machinability of Aluminum Alloy 6061 in EDM is to beanalyzed in terms of Material Removal Rate (MRR), Tool Wear Rate (TWR) and Surface roughness (Ra) by considering the following EDM process parameters viz. Pulse On Time (Ton), Current (I), Voltage (V), Pulse Off Time (Toff). Dielectric flashing circulation pressure is kept constant through out the process. Taguchi method of $L 9$ orthogonal arrayisused to determine the optimal factors of electro discharge machining process is used to investigate feasibility of design of experiment techniques.

KEYWORDS: Aluminum Alloy 6061; Electro Discharge Machining (EDM); Material Removal Rate (MRR); Surface Roughness (Ra); Taguchi Design Orthogonal Array
\end{abstract}

Received: Jun 08, 2020; Accepted: Jun 28, 2020; Published: Sep 03, 2020; Paper Id.: IJMPERDJUN20201039

\section{INTRODUCTION}

Education and knowledge are important keys for human being. The correlation between education and the prosperity of society is well established. The importance of education has been universally acknowledged and accepted, but the phenomenon of exclusion of larger sections of the population and the drop outs from the formal education systems is one constraint. Academic and professional up-gradation, the professional training that would enhance the performance in traditional occupations and the intellectual growth, is required in today's time.

Electric discharge machining is a thermo electric nontraditional machining process. Material is removed from the work piece through localized melting and vaporization of material. Electric sparks are generated between two electrodes when the electrodes are held at as mall distance from each other in a dielectric medium and a high potential difference is applied across them. Localized regions of high temperatures are formed due to the sparks occurring between the two electrodes surfaces. Work piece material in this localized zone melts and vaporizes. Most of the molten and vaporized material is carried away from the inter electrode gap by the dielectric flow in the form of debris particles.

In this process a high strength aluminum alloy 6061 is used as electrode tool on EDM operations on EN8 carbon steel work material. A comparative study is done on MRR, TWR and surface roughness by taking different 
electrodes viz. Graphite, Copper and Brass. Input parameters considered are Pulse on Time, Current, Voltage and Pulse Off Time. Design Of Experiment (DOE) is carried out to perform good accurate and more efficient experiments. Taguchi's robust design is an important tool for the design of experiments with a structured approach to improve the performance. Taguchi design and orthogonal array (OA) are two major tools used in this experiment.

\section{MATERIALS AND METHODOLOGIES}

Electrode tool material having $10 \mathrm{~mm}$ solid diameter and $100 \mathrm{~mm}$ length aluminum alloy 6061 is used as electrode tool on EDM operations on EN8 carbon steel work material. A comparative study is done on MRR, TWR and surface roughness by taking different electrodes viz. Graphite, Copper and Brass. Input parameters considered are pulse-on.Composition of $\mathrm{Al}$ alloy and EN8 work material are given in Table 1 and Table 2.

The Taguchi optimization method was selected to maximize the mechanical properties of work piece. The four variable parameter Pulse on Time $\left(\mathrm{T}_{\text {on }}\right)$, Current $(\mathrm{I})$, Voltage $(\mathrm{V})$ and Pulse off Time $\left(\mathrm{T}_{\text {off }}\right)$ and their three levels were selected, the EDM process parameter are given in the Table 3.

Table 4 shows after conducting 9 operations according to DOE initial and final weight of each work piece is measured, to find out MRR. Weights of each tool before and after operation is measured to find out TWR of electrodes and surface roughness of work pieces are measured.

After considering process parameters for each electrode and operations are performed. A total of 36 trials are done.

Table 1: Electrode Material Composition

\begin{tabular}{|c|c|}
\hline Component & Amount (wt. \%) \\
\hline Aluminum & Balance \\
\hline Magnesium & $0.8-1.2$ \\
\hline Silicon & $0.4-0.8$ \\
\hline Copper & 0.150 .4 \\
\hline Zinc & 0.050 .25 \\
\hline Manganese & 0.050 .15 \\
\hline Iron & $0.05-0.7$ \\
\hline Chromium & $0.04-0.35$ \\
\hline
\end{tabular}

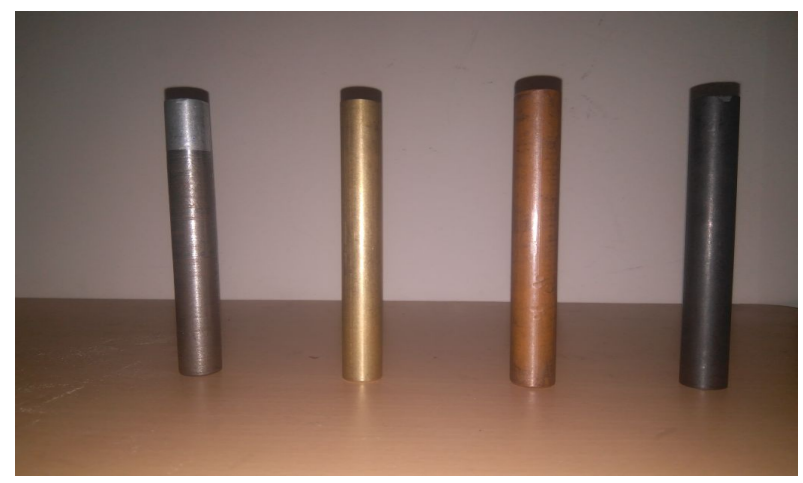

Figure 1: Al6061, Brass, Copper, Graphite.

Table 2: EN8 Specification

\begin{tabular}{|c|c|}
\hline Carbon & $0.360 .44 \%$ \\
\hline Silicon & $0.100 .40 \%$ \\
\hline Manganese & $0.601 .00 \%$ \\
\hline Sulphur & $0.050 \mathrm{Max}$ \\
\hline
\end{tabular}




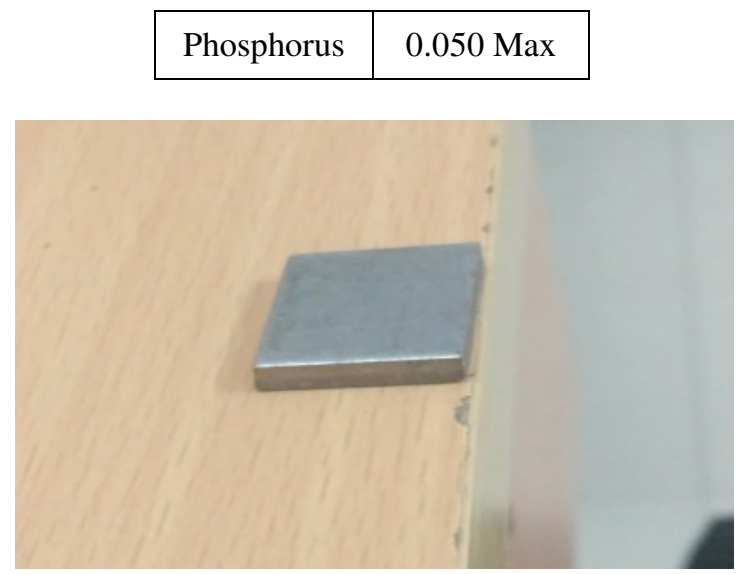

Figure 2: Work Piece after Polishing.

Table 3: EDM Process Parameter and Three Levels

\begin{tabular}{|c|c|c|c|c|c|}
\hline S. NO & Process Parameters & Unit & Level 1 & Level 2 & Level 3 \\
\hline 1 & $\begin{array}{c}\text { Pulse On } \\
\text { Time }\end{array}$ & $\mu \mathrm{s}$ & 200 & 500 & 900 \\
\hline 2 & Current & amps & 6 & 8 & 10 \\
\hline 3 & Voltage & Volts & 30 & 40 & 45 \\
\hline 4 & $\begin{array}{c}\text { Pulse Off } \\
\text { Time }\end{array}$ & $\mu \mathrm{s}$ & 100 & 200 & 500 \\
\hline
\end{tabular}

Table 4: Design of Experiments as Per Taguchi L9 Orthogonal Array

\begin{tabular}{|c|c|c|c|c|}
\hline Units & $(\boldsymbol{\mu s})$ & $(\mathbf{A})$ & $(\mathbf{V})$ & $(\boldsymbol{\mu s})$ \\
\hline S.NO & $\begin{array}{c}\text { Pulse On } \\
\text { Time }\end{array}$ & Current & Voltage & $\begin{array}{c}\text { Pulse Off } \\
\text { Time }\end{array}$ \\
\hline 1 & 200 & 6 & 30 & 100 \\
\hline 2 & 200 & 8 & 40 & 200 \\
\hline 3 & 200 & 10 & 45 & 500 \\
\hline 4 & 500 & 6 & 30 & 500 \\
\hline 5 & 500 & 8 & 40 & 100 \\
\hline 6 & 500 & 10 & 45 & 200 \\
\hline 7 & 900 & 6 & 30 & 200 \\
\hline 8 & 900 & 8 & 40 & 500 \\
\hline 9 & 900 & 10 & 45 & 100 \\
\hline
\end{tabular}

\subsection{Mechanism of Material Removal Rate}

Mechanism behind metal removal of EDM process is based on the transformation of electrical energy to thermal energy that categorized it to electro thermal process. At a given moment at least point suitable Voltage is created produces electrostatic comes up short for emission of electrons from the cathode there electrons accelerated towards the anode after getting velocity of electrons collides with the dielectric particles breaking them into negative and positive particles because of that spark is created with high temperature causes dissolving and vaporization of material from the work piece.

\subsection{Formula of MRR Calculation}

MRR is calculated as the proportion of the change of weight of the workpiece before and after machining to the product of machining period and density of workpiece material.

$$
\mathbf{M R R}=\frac{W 1-W 2}{t \times \rho}
$$

Whereas:W1 = Weight of workpiece before machining.W2= Weight of workpiece after machining. 
$\mathrm{t}=$ Machining period $=10$ min. $\boldsymbol{\rho}=$ Density of EN8 workpiece

\subsection{Formula of TWR Calculation}

TWR is calculated as the extent of the change of weight of the electrode tool before and after machining to the product of machining period and density of the tool material.

$$
\mathbf{T W R}==\frac{W 3-W 4}{t \times \rho}
$$

Whereas: $\mathrm{W}_{3}=$ Weight of electrode tool before machining, $\mathrm{W}_{4}=$ weight of electrode tool after machining.

$\mathrm{T}=$ Machining period=10 min. $\boldsymbol{\rho}=$ Density of electrode tool

The calculation of material removal rate has been done by using electronic sense of balance weight machine as shown below. For each weight measurement first clean the tool andworkpiece with a cloth or cotton to prevent from extra weight. This weighing machine having capability to weigh up to $300 \mathrm{~g}$ with accuracy of $0.001 \mathrm{~g}$.

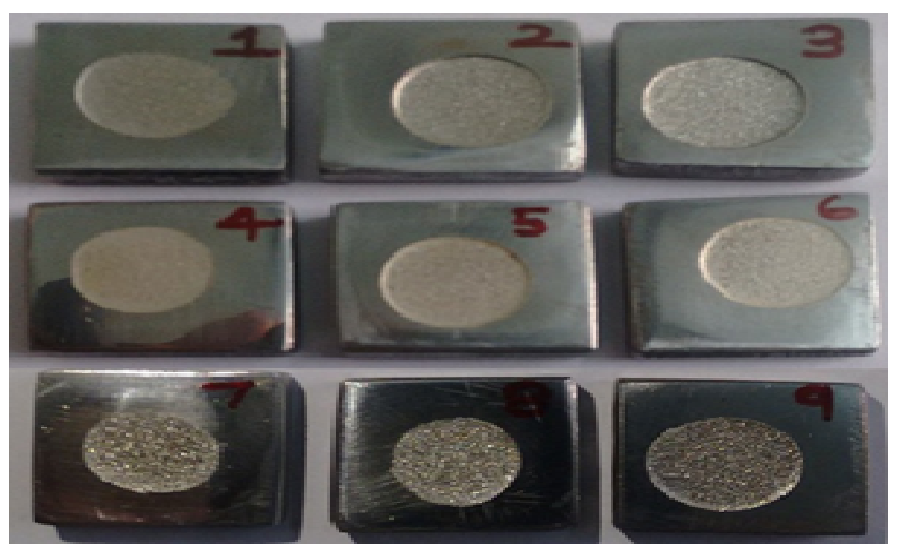

Figure 3: Work Piece after Machining

\section{EXPERIMENTAL RESULTS}

It is observed that from Table VI the order of effect of input process parameters for graphite is Pulse on Time, Current, Voltage, and Pulse off Time. From Figure 4 MRR is maximum at Pulse on Time $200 \mu \mathrm{s}$, Current 8 A, Voltage 45 volts and Pulse off Time $200 \mu \mathrm{s}$.

It is observed that from Table 7 the order of effect of input process parameters of graphite for surface roughness are Voltage, Pulse on Time, Pulse off Time and Current. From Figure 5 surface roughness is minimum at Pulse on Time

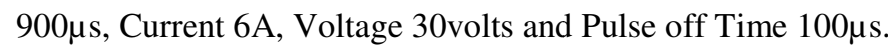

It is observed that from Table VIII the order of effect of input process parameters for Al6061 are Pulse on Time Current, Voltage, and Pulse off Time. From Figure 6 MRR is maximum at Pulse on Time $500 \mu$ s, Current 8 A, Voltage 30volts and pulse-off time $100 \mu \mathrm{s}$.

It is observed that from Table 9 the order of effect of input process parameters of Al6061for surface roughness are Current, Pulse off Time, Voltage and pulse on time. From Figure 7 surface roughness is minimum at Pulse on Time 900 $\mu$ s, Current 10A, Voltage 30volts and Pulse off Time 100 $\mu$ s.

It is observed that from Table 10 the order of effect of input process parameters of copper for surface roughness 
are Voltage, pulse-on, Current and Pulse off Time. From Figure 8 surface roughness is minimum at Pulse on Time 500 $\mu$ s, Current 6A, Voltage 30volts and Pulse off Time 500 $\mathrm{s}$.

It is observed that from Table 11 the order of effect of input process parameters of copper for surface roughness

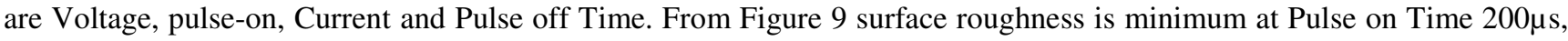

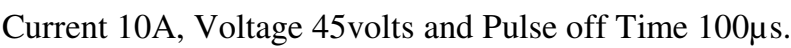

It is observed that from Table 12 the order of effect of input process parameters for brass are Current, Voltage, Pulse off Time and Pulse on Time. From Figure 10 MRR is maximum at Pulse on Time 200 $\mu$ s, Current 10A, Voltage

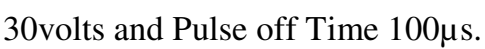

It is observed that from Table 13 the order of effect of input process parameters of brass for surface roughness are Current, Pulse on Time, Pulse off Time and Voltage. From Figure 11 surface roughness is minimum at Pulse on Time

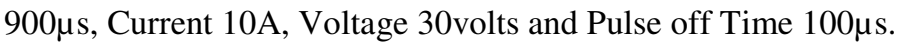

Table 5: Response Parameters Values

\begin{tabular}{|c|c|c|c|c|c|c|c|c|}
\hline \multirow{3}{*}{ S.No } & \multicolumn{8}{|c|}{ Response Parameters } \\
\cline { 2 - 9 } & \multicolumn{2}{|c|}{ Graphite } & \multicolumn{2}{c|}{ Al 6061 } & \multicolumn{2}{c|}{ Copper } & \multicolumn{2}{c|}{ Brass } \\
\cline { 2 - 9 } & MRR & SR & MRR & SR & MRR & SR & MRR & SR \\
\hline 1 & 0.03632 & 5.732 & 0.02777 & 3.95 & 0.01709 & 3.11 & 0.0235 & 2.67 \\
\hline 2 & 0.0641 & 2.616 & 0.03205 & 3.293 & 0.00427 & 2.738 & 0.05555 & 3.608 \\
\hline 3 & 0.10256 & 4.387 & 0.06196 & 3.819 & 0.01495 & 5.473 & 0.05128 & 4.088 \\
\hline 4 & 0.01709 & 3.608 & 0.06196 & 2.258 & 0.01282 & 1.872 & 0.01495 & 2.53 \\
\hline 5 & 0.0876 & 5.473 & 0.21581 & 4.071 & 0.01709 & 2.872 & 0.04487 & 5.111 \\
\hline 6 & 0.07692 & 5.26 & 0.18803 & 4.237 & 0.01923 & 2.895 & 0.05555 & 5.026 \\
\hline 7 & 0.02777 & 6.829 & 0.05341 & 3.562 & 0.0235 & 3.9 & 0.01709 & 2.405 \\
\hline 8 & 0.06196 & 5.454 & 0.15598 & 4.012 & 0.04487 & 3.124 & 0.047 & 4.765 \\
\hline 9 & 0.02991 & 5.59 & 0.1517 & 4.523 & 0.02564 & 3.6 & 0.07264 & 5.806 \\
\hline
\end{tabular}

Table 6: Response Table of Graphite for MRR

\begin{tabular}{|c|c|c|c|c|}
\hline Level & $\mathbf{T}_{\text {ON }}(\boldsymbol{\mu s})$ & $\mathbf{I}(\mathbf{A})$ & $\mathbf{V}(\mathbf{V})$ & $\mathbf{T}_{\text {OFF }}(\boldsymbol{\mu s})$ \\
\hline 1 & 0.06766 & 0.02707 & 0.05840 & 0.05128 \\
\hline 2 & 0.06054 & 0.07123 & 0.03704 & 0.05627 \\
\hline 3 & 0.03989 & 0.06980 & 0.07265 & 0.06054 \\
\hline Delta & 0.02778 & 0.04416 & 0.03561 & 0.00926 \\
\hline Rank & 3 & 1 & 2 & 4 \\
\hline
\end{tabular}

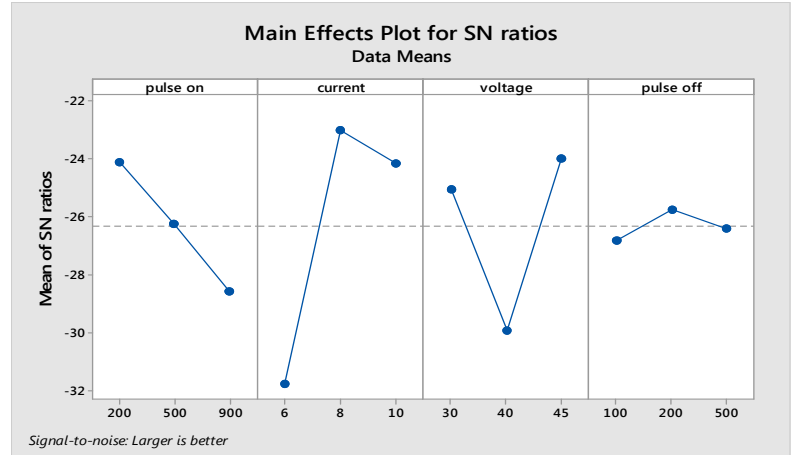

Figure 4: Material Removal Rate.

Table 7: Response Table of Graphite For Surface Roughness

\begin{tabular}{|c|c|c|c|c|}
\hline Level & $\mathbf{T}_{\text {ON }}(\boldsymbol{\mu s})$ & $\mathbf{I}(\mathbf{A})$ & $\mathbf{V}(\mathbf{V})$ & $\mathbf{T}_{\text {OFF }}(\boldsymbol{\mu s})$ \\
\hline 1 & 4.245 & 5.285 & 5.482 & 5.598 \\
\hline
\end{tabular}




\begin{tabular}{|c|c|c|c|c|}
\hline 2 & 4.675 & 4.514 & 3.833 & 4.902 \\
\hline 3 & 5.958 & 5.079 & 5.563 & 4.378 \\
\hline Delta & 1.713 & 0.770 & 1.730 & 1.220 \\
\hline Rank & 2 & 4 & 1 & 3 \\
\hline
\end{tabular}

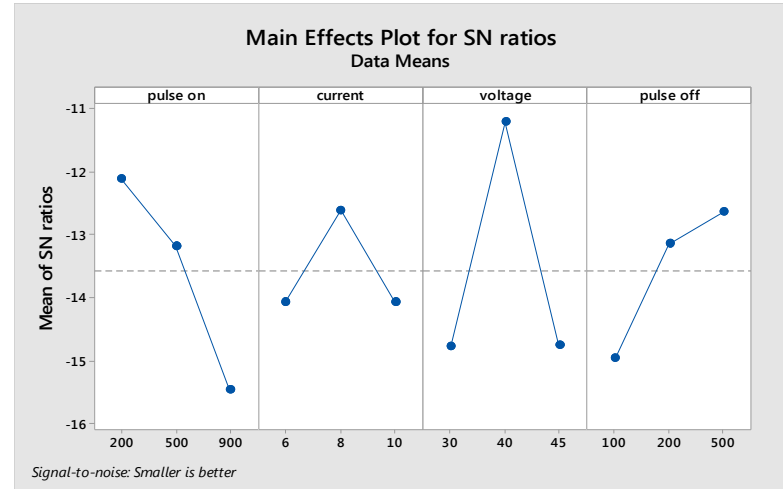

Figure 5 Surface Roughness.

Table 8: Response Table of Al6061 for MRR

\begin{tabular}{|c|c|c|c|c|}
\hline Level & $\mathbf{T}_{\text {ON }}(\boldsymbol{\mu s})$ & $\mathbf{I}(\mathbf{A})$ & $\mathbf{V}(\mathbf{V})$ & $\mathbf{T}_{\text {OFF }}(\boldsymbol{\mu s})$ \\
\hline 1 & 0.04060 & 0.04772 & 0.12393 & 0.13177 \\
\hline 2 & 0.15527 & 0.13462 & 0.08191 & 0.09117 \\
\hline 3 & 0.12037 & 0.13390 & 0.11040 & 0.09330 \\
\hline Delta & 0.11467 & 0.08689 & 0.04202 & 0.04060 \\
\hline Rank & 1 & 2 & 3 & 4 \\
\hline
\end{tabular}

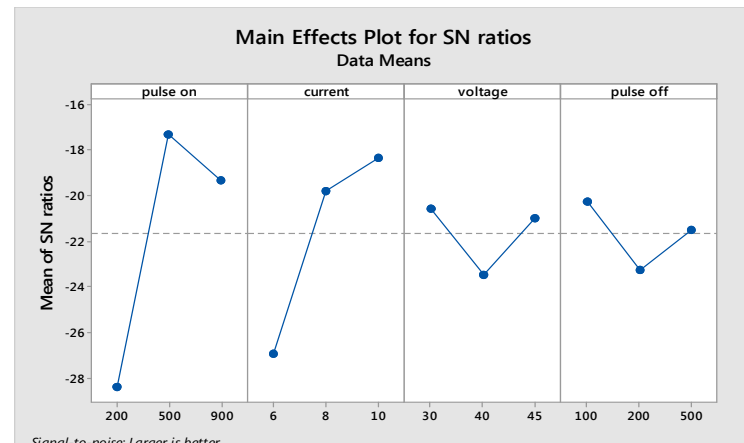

Figure 6: Material Removal Rate.

Table 9: Response Table of Al6061 for Surface Roughness

\begin{tabular}{|c|c|c|c|c|}
\hline \multicolumn{1}{|c|}{ Level } & \multicolumn{1}{c}{$\mathbf{T}_{\text {ON }}(\boldsymbol{\mu s})$} & \multicolumn{1}{c|}{$\mathbf{I}(\mathbf{A})$} & $\mathbf{V}(\mathbf{V})$ & $\mathbf{T}_{\text {OFF }}(\boldsymbol{\mu s})$ \\
\hline 1 & 3.780 & 3.257 & 4.066 & 4.181 \\
\hline 2 & 3.522 & 3.884 & 3.450 & 3.790 \\
\hline 3 & 4.032 & 4.193 & 3.817 & 3.363 \\
\hline Delta & 0.510 & 0.936 & 0.616 & 0.818 \\
\hline Rank & 4 & 1 & 3 & 2 \\
\hline
\end{tabular}




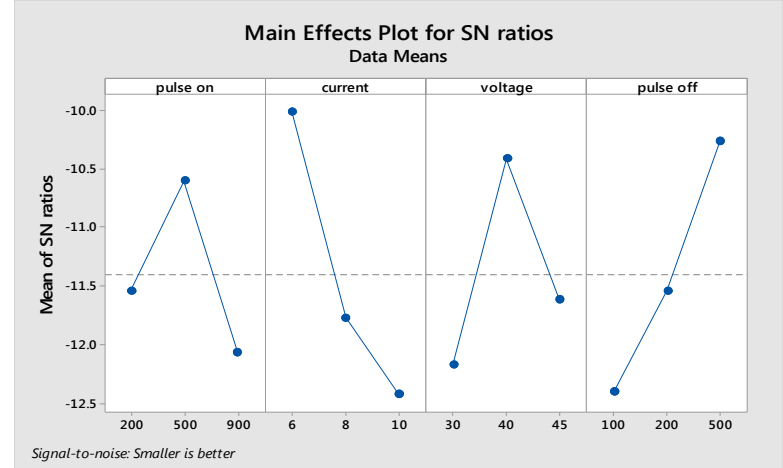

Figure 7: Surface Roughness.

Table 10: Response Table of Copper for MRR

\begin{tabular}{|c|c|c|c|c|}
\hline Level & $\mathbf{T}_{\text {ON }}(\boldsymbol{\mu s})$ & $\mathbf{I}(\mathbf{A})$ & $\mathbf{V}(\mathbf{V})$ & $\mathbf{T}_{\text {OFF }}(\boldsymbol{\mu s})$ \\
\hline 1 & 0.01211 & 0.01781 & 0.02707 & 0.01994 \\
\hline 2 & 0.01638 & 0.02208 & 0.01425 & 0.01567 \\
\hline 3 & 0.03134 & 0.01994 & 0.01852 & 0.02422 \\
\hline Delta & 0.01923 & 0.00427 & 0.01282 & 0.00855 \\
\hline Rank & 1 & 4 & 2 & 3 \\
\hline
\end{tabular}

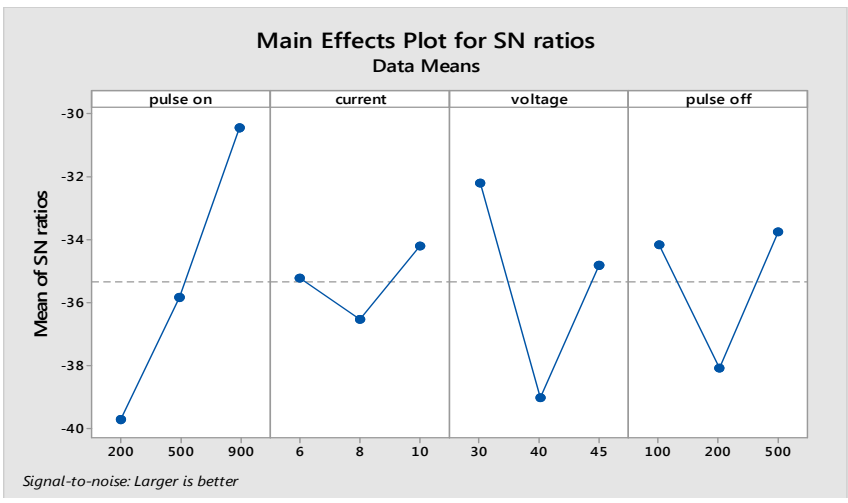

Figure 8: Material Removal Rate.

Table 11: Response Table of Copper for Surface Roughness

\begin{tabular}{|c|c|c|c|c|}
\hline Level & $\mathbf{T}_{\text {ON }}(\boldsymbol{\mu s})$ & $\mathbf{I}(\mathbf{A})$ & $\mathbf{V}(\mathbf{V})$ & $\mathbf{T}_{\text {OFF }}(\boldsymbol{\mu s})$ \\
\hline 1 & 3.704 & 2.961 & 3.043 & 3.194 \\
\hline 2 & 2.546 & 2.911 & 2.737 & 3.178 \\
\hline 3 & 3.541 & 3.920 & 4.012 & 3.420 \\
\hline Delta & 1.158 & 1.009 & 1.276 & 0.243 \\
\hline Rank & 2 & 3 & 1 & 4 \\
\hline
\end{tabular}

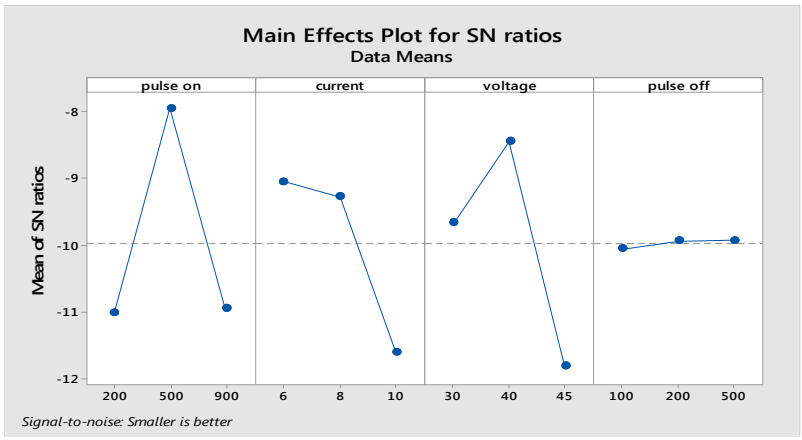

Figure 9: Surface Roughness. 
Table 12 Response Table of brass for MRR

\begin{tabular}{|c|c|c|c|c|}
\hline Level & $\mathbf{T}_{\text {ON }}(\boldsymbol{\mu s})$ & $\mathbf{I}(\mathbf{A})$ & $\mathbf{V}(\mathbf{V})$ & $\mathbf{T}_{\text {OFF }}(\boldsymbol{\mu s})$ \\
\hline 1 & 0.04345 & 0.01852 & 0.04202 & 0.04701 \\
\hline 2 & 0.03846 & 0.04915 & 0.04772 & 0.04274 \\
\hline 3 & 0.04558 & 0.05983 & 0.03775 & 0.03775 \\
\hline Delta & 0.00712 & 0.04131 & 0.00997 & 0.00926 \\
\hline Rank & 4 & 1 & 2 & 3 \\
\hline
\end{tabular}

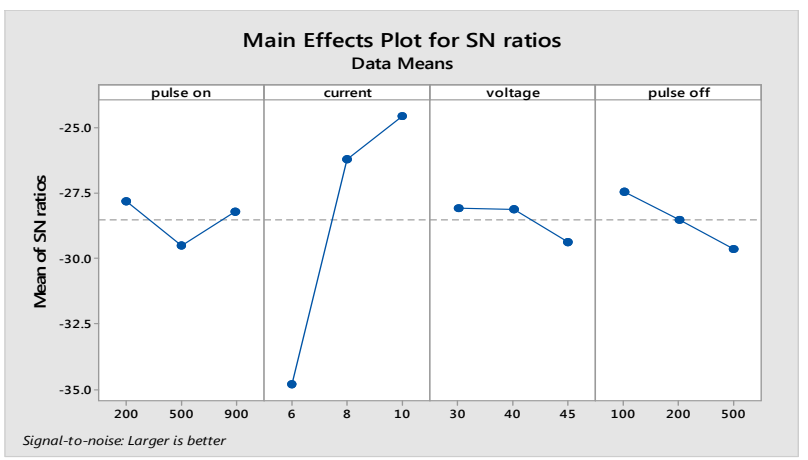

Figure 10: Material Removal Rate.

Table 13: Response Table of Copper for Surface Roughness

\begin{tabular}{|c|c|c|c|c|}
\hline Level & $\mathbf{T}_{\text {ON }}(\boldsymbol{\mu s})$ & $\mathbf{I}(\mathbf{A})$ & $\mathbf{V}(\mathbf{V})$ & $\mathbf{T}_{\text {OFF }}(\boldsymbol{\mu s})$ \\
\hline 1 & 3.455 & 2.535 & 4.154 & 4.529 \\
\hline 2 & 4.222 & 4.495 & 3.981 & 3.680 \\
\hline 3 & 4.325 & 4.973 & 3.868 & 3.794 \\
\hline Delta & 0.870 & 2.438 & 0.286 & 0.849 \\
\hline Rank & 2 & 1 & 4 & 3 \\
\hline
\end{tabular}

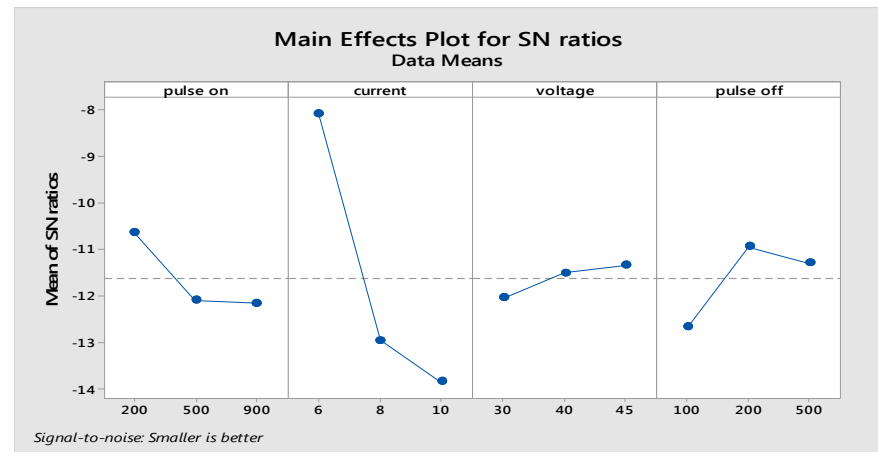

Figure 11: Surface Roughness.

Table 14: Tool Wear Rate

\begin{tabular}{|c|c|c|c|c|}
\hline Units & (Grams) & (Grams) & (Grams) & $\left(\mathbf{G m} / \mathbf{M m}^{\mathbf{3}}\right)$ \\
\hline S.No & Initial Weight & Final Weight & Difference & TWR \\
\hline Graphite & 22.90 & 22.48 & 0.42 & 0.3092 \\
\hline Al6061 & 85.26 & 85.07 & 0.19 & 0.1172 \\
\hline Copper & 118.71 & 118.23 & 0.48 & 0.089 \\
\hline Brass & 97.03 & 95.48 & 1.55 & 0.2959 \\
\hline
\end{tabular}

\section{RESULTS AND CONCLUSIONS}

In this experimention on EDM to know the effect of machining outputs taken for consideration are material removal rate and surface roughness of the EN8 work piece using the AL6061 tool with side flushing method have been investigated. Both these outputs are important in industrial applications. 
The experiment depends upon various parameters settings such as peak Current $\left(\mathrm{I}_{\mathrm{p}}\right)$, pulse on time $\left(\mathrm{T}_{\text {on }}\right)$, Pulse off time $\left(\mathrm{T}_{\mathrm{off}}\right)$, Voltage $(\mathrm{V})$ and Electrode material have been selected. Based on L9 orthogonal array by taguchi design, experiment was conducted and MINITAB software is used for the analysis of experiment.

- Compared to graphite has highest material removal rate and greater surface finish than all remaining electrodes.

- Compared to Brass, Al6061 is giving lesser tool wear rate and more material removal rate. Surface roughness is also less compared to brass.

- Compared to copper, has slightly more material removal rate and less tool wear rate than Al6061. Surface roughness is less in case of Al6061 when compared to copper. Also Al6061 is commercially cheaper than copper.

\section{REFERENCES}

1. Ankur Srivastava, Kumar Abhishek, SuravDatta, ChandramaniUpadhyaya, Siba Sankar Mahapatra, Effect of variation of electrode material on machining performance of Al 6061 during EDM operation, Department of Mechanical Engineering FST, IFHE, Hyderabad, INDIA Department of Mechanical Engineering National Institute of Technology, Rourkela, Odisha, India.

2. Alavala, CHENNAKESAVA R. "Effect of Temperature, Strain Rate and Coefficient of Friction on Deep Drawing Process of 6061 Aluminum Alloy." International Journal of Mechanical Engineering 5.6 (2016): 11-24.

3. N.Arunkumar, H.Shareef, AbdurRawoof and R.Vivek, Investigation on the Effect of Process Parameters for Machining of EN31 (Air Hardened Steel) By EDM, International Journal of Engineering Research and Applications (IJERA) ISSN: 22489622, Vol. 2, Issue4, July-August 2012, pp.11111121.

4. Mr. V.D.Patel, Prof. C. P. Patel, Mr. U.J. Patel, Analysis of Different Tool Material On MRR and Surface Roughness of Mild Steel In EDM, International Journal of Engineering Research and Applications (IJERA) ISSN: 2248-9622, Vol. 1, Issue 3, pp. $394-397$.

5. REDDY, A. CHENNAKEESAVA. "Low and High Temperature Micromechanical Behavior of BN/3003 Aluminum Alloy Nanocomposites." International Journal of Mechanical Engineering and Technology 6.4 (2017): 2734.

6. Manish Vishwakarma, V.K. Khare, VishalParashar, Response Surface approach for optimization of Sinker EDM process parameters on AISI 4140 alloy steel, International Journal of Engineering Research and Applications (IJERA), Volume 2, Issue 4, July-August 2012.

7. Sandeep, MetalRemoval Rate Optimization in Electric Discharge Machining Process, International Journal of Enhanced Research in Science Technology \& Engineering, ISSN: 2319-7463 Vol. 3 Issue 10, October-2014.

8. Omar, ADEL A., M. El-Shennawy, and M. Ayad. "Study of Wear Behavior of as Cast TiC/7075 Composite." International Journal of Mechanical Engineering 4.4 (2015): 4552.

9. ShivaniYadav, Manoj Kumar Gaur, Parametric optimization of MRR \& TWR on Electro Discharge Machining by using Taguchi's Method and ANOVA, International Journal of Electronics, Electrical and Computational System IJEECS ISSN 2348-117X Volume 5, Issue 5 May 2016.

10. PrashantYadava, Avdesh Chandra Dixit, Jitendra Kumar Verma, Optimization of EDM Parameter of High Carbon-High Chromium Steel (AISI D3) by using Brass Electrode, International Journal of Engineering Trends and Technology (IJETT) Volume 34 Number 3- April 2016.

11. P Shankar, $R$ Boopathi and M Prabu, Investigating the Effect of Brass Electrode on Inconel 718 on ElectricalDischarge Machine, IJISET - International Journal of Innovative Science, Engineering \& Technology, Vol. 2 Issue 4, April 2015 
12. Alavala, CHENNAKESAVA R. "FEM analysis of single point incremental forming process and validation with grid-based experimental deformation analysis." International Journal of Mechanical Engineering 5.5 (2016): 1-6.

13. Sandeep Kumar, Prof. Ishwar Chand Ramola, Ranjeet Kumar, Analysis of Surface Roughness and Material Removal Rate for High Carbon High Chromium Steel on Die Sinking EDM using Taguchi Technique, SSRG International Journal of Mechanical Engineering (SSRG-IJME) - EFES April 2015.

14. Nayan Patel, Review on Importance of Electrodes in Electrical Discharge Machining Process, International Journal of Research in Aeronautical and Mechanical Engineering. 